\section{NOTES ON METEORITES.'}

IV.

Meteorites are Bodies which, like the Earth itself, revolve round the Sun.

$W^{E}$ have seen that the phenomena which accompany meteorites entering our air, whether they are soon burnt up and give rise only to the appearance of a shooting or falling star, or whether they are bulky enough to withstand the melting procesi till they reach the earth's surface, are similar. We are now in a position to discuss the origin of all these phenomena on the assumption that they have a common cause.

It is not so many years ago since the planetary spaces were supposed to be untenanted by anything more tangible than that mysterious fluid called ether. This notion is exactly represented by the French equivalent for those spaces, le vide planétaire. Hence, not to mention imagined supernatural causes-such as that, for instance, embodied in the tradition that Saint Lawrence, on the anniversary of his martyrdom (August 10), shed burning tears-the cause of the phenomenon was ascribed to atmospheric perturbations, exhalations of sulphur, irnes fatui, and so forth. An account of the August shower of 1857 , even, published in the Bulletin de l'Académie Royale de Belgique, is accompanied by a minute record of rain, temperature, atmospheric electricity, \&c.

Leaving out of consideration the opinions of the ancients, among whom Anaxagoras and Seneca may be especially mentioned, as being in favour of a cosmical origin, it may be pointed out that Kepler ${ }^{2}$ regarded meteorites and shooting-stars as akin, and derived both from the ethereal regions.

Halley was the next to express an opinion that shooting-stars were of cosmical origin, but to Chladni belongs the credit of having broached the theory which modern observations have so abundantly justified. This theory was that space was full of the matter which, attracted by the earth, entered its atmosphere, accompanied by luminous effects only in some cases, and by actual falls of the matter in others. ${ }^{3}$ The general acceptance of this view was retarded by Laplace and others, who saw a more probable origin for the phenomena by suppo-ing meteorites to be masses shot out of lunar volcanoes. The first step in the demonstration of such an origin, which is now universally accepted, was made when Chladni, ${ }^{4}$ in $\mathbf{1 7 9 4}$, showed that no known terrestrial agency was capable of producing masses like the meteorites which had been seen to fall. At his and Lichtenbergh's suggestion, Brandes and Benzenberg in 1798 showed that, whatever they appear to do, shooting-stars never shoot upwards, but always downwards towards the earth. At the same time he showed the similarity of phenomena presented by fire-balls, shooting-stars, and the fall of meteorites, to which we have already called attention. He subsequently returned to and strengthened this view. ${ }^{5}$

"Should it be asked how such masses originated, or by what means they were brought into such an insulated position, this question would be the same as if it were asked how the planets originated. Whatever hypothesis we may form, we must either admit that the planets, if we except the many revolutions which they may have undergone, either on or near their surface, have always been since their first formation, and ever will be, the same; or that Nature, acting on created matter, possesses the power to produce worlds and whole systems, to destroy them, and from their materials to form new ones. For the latter opinion there are, indeed, more grounds than the former, as alternations of destruction and creation are exhibited by all organized and unorganized bodies on our earth; which gives us reason to suspect that Nature, to which greatness and smallness, considered in general, are merely relative terms, can produce more effects of the same kind on a larger scale.

"But many variations have been observed on distant bodies, which, in some measure, render the last opinion probable ; for example, the appearing and total disappearing of certain stars, when they do not depend upon periodical changes. If we now admit that planetary bodies have started into existence, we can. not suppose that such an event can have otherwise taken place, than by conjecturing that either particles of matter, which were before dispersed throughout infinite space, in a more soft and

"Continued fron p. 533. 2 "Opera," ed. Fritsch, vol. vi. p. ${ }_{357 .}$ 3 "Ueber den Urspring der von Pallas gefundenen Eisenmassen," p. 24. vol. ii., 1798 .

S See Phil. Mag., Tillock, vol. ii. p. 225, et seq. chaotic condition, have united together in large masses, by the power of attraction; or that new planetary bodies have been formed from the fragments of much larger ones that bave been broken to pieces, either perhaps by some external shock, or by an internal explosion. Let whichever of these hypotheses be the truest, it is not improbable, or at least contrary to nature, if we suppose that a large quantity of such material particles, either on account of their too great distance, or because prevented by a stronger movement in another direction, may not have united themselves to the larger accumulating mass of a new world; but have remained insulated, and, impelled by some shock, have continued their course through infinite space, until they approach so near to some planet as to be within the sphere of its attraction, and then by falling down to occasion the phenomena before mentioned.

"It is worthy of remark that iron is the principal component part of all the masses of this kind hitherto discovered; that it is found almost everywhere on the surface of the earth as a com ponent part of many substances in the vegetable and animal kingdom; and that the efferts of magnetism give us reason to conclude that there is a large provision of it in the interior part of the earth. We may therefore conjecture that iron in general is the principal matter employed in the formation of new planetary bodies; and is still farther probable by this circumstance, that it is exclusively connected with the magnetic power, and also on account of their polarity may be necessary to these bodies. It is also probable, if the above theory be just, that other substances contained in such fallen masses, such as sulphur, siliceous earth, manganese, \&c., may be peculiar, not to our globe alone, bu may belong to the common materials employed in the formation of all planetary worlds"

This paper of Chladni's, it will be seen, dates from just before the beginning of the present century.

The subject was invested with a new interest in 1799 , when the great Humboldt, who was then travelling in South America, saw an enormous quantity of shooting-stars covering the sky. In his long account of the shower in his "Personal Narrative," he states that, from the beginning of the phenomenon, there was not a space in the firmament equal in extent to three diameters of the moon that was not filled at every instant with bolides and falling stars; while he was locally informed that during a previous display in 1766 the inhabitants of Cumana had beheld the neighbouring volcano, Cayamba, veiled for an hour by a similar display.

In the next display, observed in the year $1833,24 \mathrm{c}, 000$ meteors were computed by Arago to have been visible above the horizon of Boston on the morning of November 13; while $\mathrm{Mr}$. Baxendell, who observed the shower from the west coast of Mexico, states that "the number of meteors seen at once often equalled the apparent number of the fixed stars seen at a glance."

Olmsted, when he bad witnessed the shower of 1833 (a shower heralded and followed by less brilliant displays in $183 \mathrm{I}-32$ and 1834-35-36), and when, moreover, he had compared the phenomena with those recorded by Humboldt and Bonpland in I799, announced the view which has since been so brilliantly confirmed-that the appearances are due to the passage of the earth through a storm, so to speak, of planetary bodies.

This was the first blow given to le iide planétaire. Space, instead of being empty, was full of bodies, some of them being congregated into rings, each body composing the ring revolving like a planet round the sun. In fact, these rings may be compared to tangible orbits; indeed, they almost realize the schoolboy's idea of an orbit, as a considerable part of the path i: occupied by a string of little planets, while in the case of our earth's orbit, for instance, each point of the path is occupied in succession ónly.

Still Olmsted did not accept the view that the falling stars were of the same nature as meteorites.

Olmsted also noted that, however numerous the falling stars might be, or in whatever direction they appeared, or what ever the apparent lengths of their paths, the lines of motion of these paths, retraced along the sky, nearly all found a common focus of emanation or visual crater of projection among the fixed stars. This has since been called the radiant point.

The most salient fact, noticed even by those who did not see its significance, during the subsequent display in 1866 , was that all the meteors seemed to come from the same region of the sky. Among all those seen by myself from I I p.m. on Tuesday till? a.m. on Wednesday morning, truo only were exceptions to the general direction. In fact, there was a region in which the 
meteors appeared trainless, and shone out for a moment like so many stars, because they were directly approaching us. Near this spot they were so numerous, and all so foreshortened, and for the most part faint, that the sky at times put on almost a phosphorescent appearance. As the eye travelled from this region the trains became longer, those being longest as a rule which first made their appearance overhead, or which rended westward. Now, if the paths of all had been projected backwards, they would have all intersected in one region, and that region the one in which the most foreshortened ones were seen.

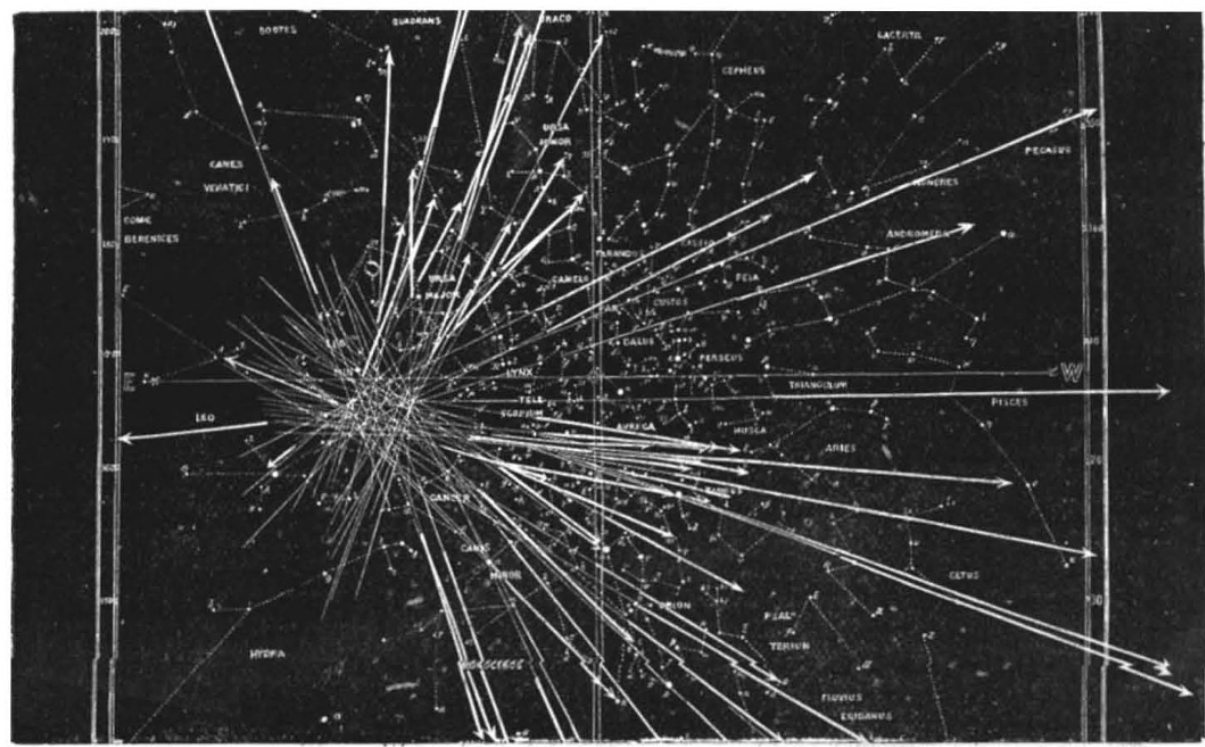

FIG. 7,-The radiant point of the November meteors.

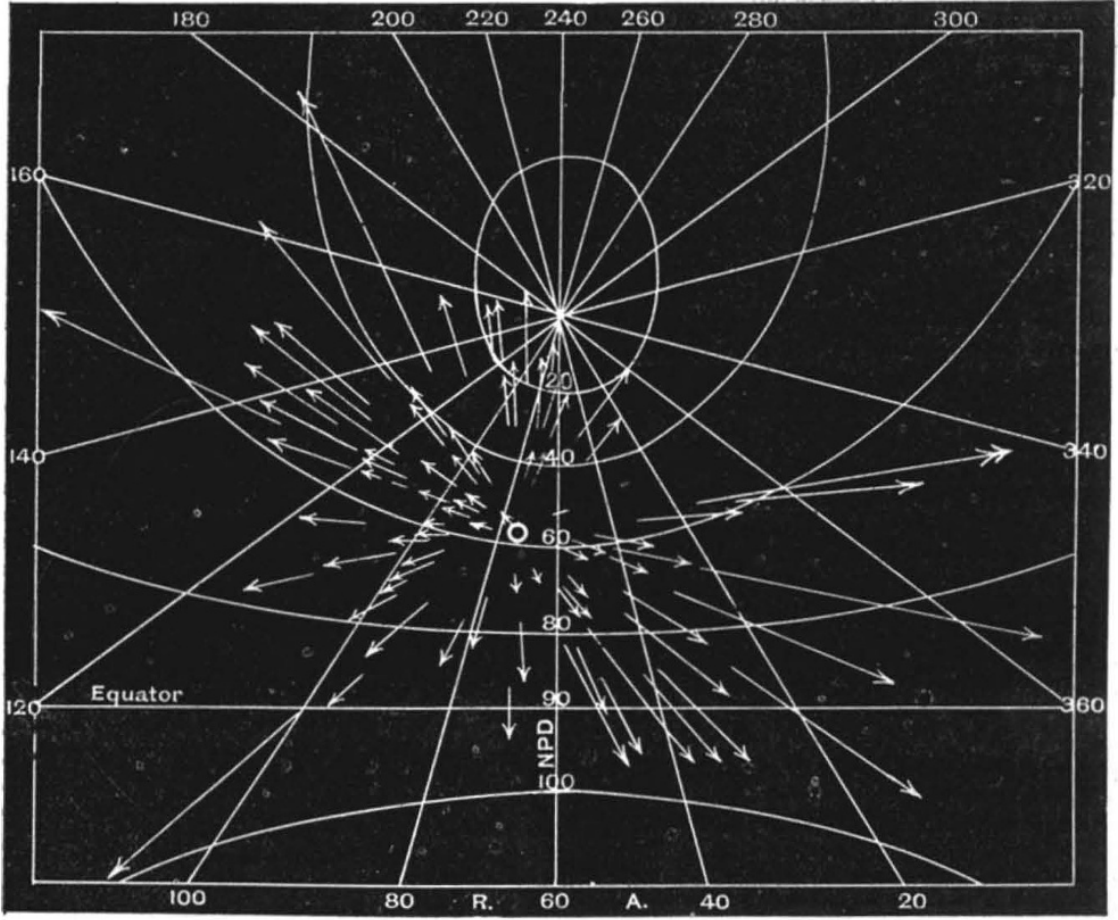

FIG. 8.-Radiant point of long duration (October-November), Denning.

So decidedly did this fact come out that there were moments in which the meteors belted the sky like the meridians on a terres. trial globe, the pole of the globe being represented by a point in the constellation Leo. In fact, they all seemed to radiate from that point, and radiant point, as we have seen, is precisely the name given to it by astronomers. Vanishing point, if the bull were permissible, is a term which would represent the fact rather than the appearance which is an effect of perspective ; and hence we gather that the paths of the meteors are parallel, or nearly so, and that they come therefore from one point 
in the sky. The point from which they proceed in the case of the swarm we are now considering lies in the constellation Leo, situated in longitude $142^{\circ}$ and latitude $8^{\circ} 30^{\prime} \mathrm{N}$., according to Prof. Newton.

The radiants are generally of short duration, but Mr. Denning has shown that there are cases in which falling stars emanate from the same part of the sky for long periods of time.

One of these long-duration radiants between Auriga and Taurus is shown in the accompanying illustration (Fig. 8).

The next point, first brought to light by Olmsted, was that during a display the radiant point moves with the stars across the heavens. This is another strong argument in favour of the cosmical theory.

Meteors which are singly and occasionally observed, as we have seen, are called sporadic meteors, but in addition to these, which we may reckon to see every night, there are at certain times of the year very well known falls ; so well known that we can say at once that on the Ioth or I I th of next August more falling stars will be seen than are ordinarily visible. These are termed systematic meteors, and those to which we have just referred as appearing in November are of this class.

From 1833 to 1863 evidence was rapidly accumulated indicating that a very large proportion of the shooting-stars observed were not sporadic, but really systematic - that is to say, that at certain periods of the year meteors might be expected to diverge from their appearance in a particular part of the sky, and in greater numbers from that part than from elsewhere.

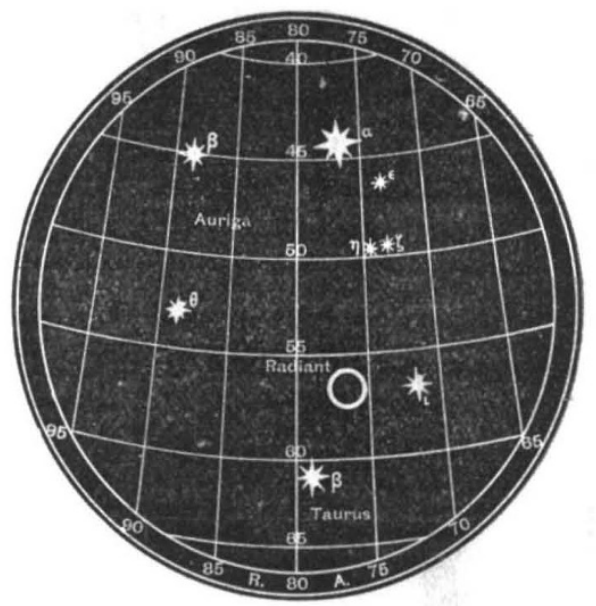

FiG. 9.-Position of the long-duration radiant among the stars.

During these years a considerable number of radiant points had been made out, and therefore the existence of a considerable number of streams or swarms had been suggested if not established. In 1863, Prof. H. A. Newton used these facts to strengthen the cosmical hypothesis.

The observations of Humboldt, modern observations, so to speak, were repeated, as we have seen, in 1833 , on the same day (or one day later) of the same month on which Humboldt had made his observation in 1799, and again one day later in 1866 there was a recurrence of the same thing. Now these dates are separated by an equal interval of thirty-three years. The idea of periodicity was therefore suggested both for this and other displays, and gave rise to so great an interest in this question that an inquiry was set afoot as to whether falls had been seen before at previous intervals of thirty-three years, or whether it was a new thing seen first by Humboldt in 1799 , or possibly by the Cumanese in 1766 .

Prof. Newton took up the inquiry, and was soon able to show that the various chronicles of star-sbowers from the very earliest times, when properly discussed, indicated that the streams suggested by the observations since 1833 had really at variouslyrecurrent intervals since the beginning of astronomical observation given indications of their existence. ${ }^{1} \mathrm{He}$ especially indicated such cases of constant recurrences of showers in April, August, November, and December.

I Silliman's Fournal, vol. xxxvi. p. 146, 1863.
The discussion of the dates of these shower; in the early records showed a constant slow change of date in one direction or the other. This obviously demonstrated that the showers were independent of the tropical year-that is to say, of the earth's motion round the sun; and it is difficult to understand how a more definite proof of their cosmical origin could be afforded.

We may conveniently confine our remarks on this point to the inquiries relating to the "Leonid" swarm of meteorites which gives rise to the November display.

Newton and others found that we possess records, dating from A.D. 902, showing that about every thirty-three years since that time the heavens have been hung with gold. The Arab historian, Abu-1'Abbas ad-Dimashkî, chronicled the November star-shower of the year $\mathbf{1} 202$ of our era in the following words, the while Chinese astronomers carefully watched the consiellations in which the meteors appeared and vanished from the sight :-

"In the year 599, on the last day of Muharram, stars shot hither and thither, and flew one against another like a swarm of locusts; this phenomenon lasted until daybreak; people were thrown into consternation, and made importunate supplications to God the most High; there was never the like seen except on the coming out of the messenger of God-on whom be benediction and peace."

This table for the November display, from Prof. Newton, shows what the result of searching the old records was :-

Epochs of November Star-Showers.

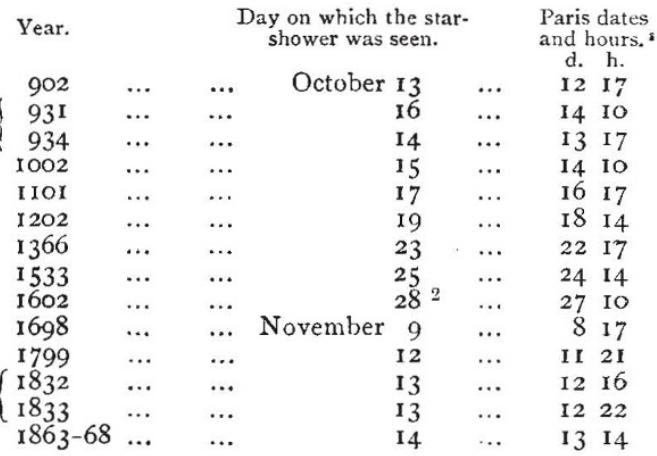

These ancient records enabled Prof. Newton to place the planetary nalure of the November ring beyond all cloubt.

It is evident that if this ring crosses our orbit in a certain definite point in space, our earth will always traverse it when it occu. pies the same definite point of its orbit with regard to the stars, provided the ring does not change its place. But our ordinary year, called the tropical year, is affected by the precession of the equinoxes, as it is measured from equinox to equinox, so that we do not measure it by the stars, but by an empirical point called the first point of the sign Aries, which is actually at the present moment in the constellation Pisces. If we refer the recorded star-showers to the sidereal year, or a fixed equinox, we should find an almost absolute identity in the dates of their appearance if there were no perturbation, but we shall see subsequently that there is perturbation, and this is a final demonstration of cosmical origin.

If there is a swarm of meteorites falling in any particular direction towards the plane of the ecliptic these meteorites will take little account of the precession of the equinoxes or the tropical year; the earth must take the meteorites as she finds them. The one great jump in the table was due to the alteration of the calendar, as there was a difference of twelve days between the old and new reckoning. Prof. Newton, Prof. Adams, and others have given a complete demonstration that from the year 902 a swarm of meteorites has been encountered by the earth every thirty-three years or thereabouts, and nearly in the same part of her orbit round the sun.

By a study of the position and lie of the earth in her orbit we can see from what part of space these meteors, these more numerous swarms, come. Suppose, for instance, that at one

'H. A. Newton, Bul. Ac. R. Belg., xvii. No. 6 .

2 In many countries the change from old to new style was made in this interval commencing frcm 1582 in Spain, Portugal, and Italy. 
part of the earth's orbit there is a stream of meteorites plunging down nearly vertically towards the ecliptic ; the earth in passing through them would receive the greatest number of blows on its exterior atmosphere on the hemisphere above the plane of the ecliptic at the time, while the other hemisphere would be entirely sheltered, so that the direction of the fall would be capable of demonstration by a consideration of the earth's direction and the relation of its surface to the plane of the ecliptic at the time.

The observations indicate that these bodies are moving towards the plane of the ecliptic, from its northern side, into that part of it through which the earth passes in her annual journey in November; they, in fact, are moving round the sun in an orbit inclined at a not very large angle $-17^{\circ}-$ to the plane of the earth's orbit.

Similarly, we might observe the August ring rising from one of its nodes, situated in the point of the earth's orbit occupied by our planet on August 10 , not at a slight angle like the November ring, but at an angle of $79^{\circ}$ or $80^{\circ}$.

It is important to make this point quite clear.

Let us conceive the sun and earth to be half immersed in an infinite ocean which will represent to us the plane of the ecliptic, and let us further for greater simplicity assume that the earth's motion round the sun (in a direction contrary to the hands of a watch) is performed in a circular path with the sun at the centre ; let us, moreover, suppose the earth's path, or orbit, to be marked by buoys, remembering that astronomers define the position of a heavenly body in the plane by stating its longi tude-that is, its angular distance, reckoning from right to left, from a particular start-point, as seen from the sun; and it latitude - that is, its angular height above the plane as seen from the same body.

Now, if it were possible to buoy various points of the earth's orbit in the plane of the ecliptic in the convenient manner before suggested, we should see the meteor-ring of "Leonids" meeting the waves of our hypothetical ocean, at a slight angle $\left(17^{\circ}\right)$, at the point of the earth's orbit occupied by our planet on November I4, the point where they pierce them being called the notle. Where the other node lies, where the meteorites cross the plane again, we do not exactly know; we only know that they do riot cross our orbit ; if they did, another star-shower would ocsur in May.

Let us inquire into this point a little more closely. Let us, in imagination, connect the earth and sun by a straight line; at any moment the direction of the earth's motion will be at right angles to that line (or a tangent to its orbit); therefore, as longitudes are reckoned, as we have seen, from right to left, the motion will be directed to a point $90^{\circ}$ of longitude behind the sun. The sun's longitude at noon on November I4 was $232^{\circ}$, within a few minutes; $90^{\circ}$ from this gives us $142^{\circ}$, which, as we have seen, is precisely the longitudle of the radiant point. This, then, is proof positive enough that in longitude at least the meteoric hail was fairly directed against, and as fairly met by, the earth.

But it will be asked, If the radiant point is situated in latitude $8^{\circ} 30^{\prime}$, how comes it that the inclination of the ring is stated to be $17^{\circ}$ ? should it not rather be $8^{\circ} 30^{\prime}$ ? To this question we may reply by another: How comes it that, when we are hurrying through a shower, we always incline an umbrella at a less angle with the ground than that formed by the falling rain? The answer is the same in both cases. In the case of the meteorites, if our motion in one direction differs little from theirs, they appear to us to fall at an angle-which is also almost precisely half of their real one.

Similar ancient records relating to star-showers seen in March and April, and July and August, showed that the earth's Iongitude was always the same when they were observed, if it was referred to a fixed equinox. The constant longitude for the star-showers anciently recorded to have taken place in March-A pril corresponds to April $20^{\circ}$ Id., 1850 , and for a like number seen in July-August, August 9 od., 1850.

Forms and dimensions of the orbit of the August meteors, all of them very steeply inclined to the ecliptic, were calculated among the many combined observations and determinations of heights of those meteors made at German Observatories to conclude their longitudes, in the years following the great November showers of $1832-33$, by the German astronomer, Erman. But an exact value of their velocity was still wanting; and from an approximate measure of the velocity of the "Perseids" obtained from observations of a fine meteor of the shower in
America on August 10, I86I, Prof. H. A. Newton found elements of the ring, concluding it to be not far from circular in form, and nearly perpendicular in its plane to the ecliptic.

It will be seen that the longitude for the showers recorded in October-November advances along the ecliptic from a fixed equinox with a uniform motion of $52^{\prime \prime}$ per annum. Such a motion as this must be due to planetary perturbation, and hence we are in presence of cosmical phenomena.

It is to an American astronomer, Prof. Newton, that we owe the first investigation into the constitution of the November ring. ${ }^{1} \mathrm{He}$ first considered the question whether the ring is of uniform density, and whether it lies merely near our orbit; the variation in the brilliancy of the showers being caused by the action of the planets and moon on the earth and ring-the greatest perturbation of the earth being 9000 miles each waysometimes throwing us into the ring, sometimes causing us to pass it without meeting it. $\mathrm{He}$ has shown, however, that the ring cannot be of uniform density throughout, but that, on the other hand, in one part of it there is a clustering together of the little bodies of which it is composed-a few stragglers being scattered along the rest of its circuit.

From other considerations be showed that the meteors revolve round the sun in a direction opposed to the earth's motion, the most probable time of revolution being, according to his first view, $354^{\circ} 62$ I days, our own being accomplished in $365^{\circ} 256$ days. "This is the same as saying that the annual motion of the group is $\mathbf{I}+\frac{\mathbf{I}}{33 \cdot 25}$ revolutions. Consequently, the centre of the group is brought, on this view, into contact with the earth once in every 133 years, but the earth passes very near the centre four times in this interval.

On this view the orbit of the swarm would be nearly circular.

With regard to the rings generally, Prof. Newton made out in $1865^{2}$ (I) that all the sporadic shooting-stars cannot belong to a narrow ring which has a diameter approaching in size that of the earth; and (2) that a large portion of the meteorites, when they meet the earth, are travelling faster than it, or else that the sporadic meteors form a series of radiants at some distance from the ecliptic, and hence come from a series of rings considerably inclined to the plane of the ecliptic.

Further, he pointed out that the distribution of the orbits of the meteorites must be one or other of the following :-

(I) They may form rings passing near the earth's orbit at many points along its circuit (sporadic meteors may be outliers of such a ring).

(2) They may form a disk in the plane of the ecliptic.

(3) They may be distributed at random like the orbits of comets.

(To be continued.) J. NORMAN LOCKYER.

SCIENTIFIC SERIALS.

American Journal of Science, September.-Cambrian fossils from Mount Stephens, North-West Territory of Canada, by Charles D. Walcott. The fossils here studied were first discovered last year by Otto J. Klotz, and partly described by Dr. C. Romiger. A comparison with specimens from the Middle Cambrian Terrane of Central Nevada shows that the two faunas are identical, and that consequently the Mount Stephens remains should be referred to about the horizon of the upper portion of the Middle Cambrian system. Other discoveries near the Kicking Horse Pass on the Canadian Pacific Railway seem to show that this fauna extends all along the western side of the great Keweenawan continental area from Southern Nevada far into British America.- - History of changes in the Mount Loa craters (continued), by James D. Dana. Here are studied the relations of Kilauea to Mount Loa, arguments being advanced to establish the independent origin of the former, contrary to the author's earlier views on the subject. But his old conclusion is con. firmed that volcanoes are not safety-valves, but are rather indexes of danger, pointing out the parts of the earth's crust that are most subject to earthquakes. A contrast is also drawn between volcanoes of the Mount Loa and Vesuvius types, the discharges of the former being almost exclusively outflows, those of the latter upthrows of cinders cumbined with lava-streams. - On the formation of deposits of oxides of manganese, by F. P. Dunnington. The main object of this paper is to show that manganese sulphate has probably taken a very important part in the

$$
\begin{aligned}
& \text { I Silliman's Journal, Nos. } 11 x \text { and } x \mathrm{z} \text {. } \\
& \text { a Ibid., vol. xxxix. }
\end{aligned}
$$

